\title{
IDEOLOGIA NEOLIBERAL E EDUCAÇÃO: UM PAR POSSÍVEL PARA A EMANCIPAÇÃO SOCIAL?
}

\author{
Ariovaldo Santos \\ Prof. Associado da Universidade Estadual de Londrina (UEL) - PR \\ arioliveira2001@yahoo.com.br \\ Elsio Lenardão \\ Prof. Dr. Universidade Estadual de Londrina \\ Depto de Ciências Sociais
}

\begin{abstract}
RESUMO:
A violência é em geral apresentada como um processo físico, resultante do uso da força bruta. No presente artigo busca-se discutir como o movimento de expansão do capital, sem romper com o primado assinalado, tornaram mais complexos os mecanismos de dominação. Assim, uma das componentes importantes no processo de dominação política e econômica, contemporânea, é a exploração do campo das manifestações simbólicas como caminho para sedimentar os interesses ligados à acumulação do capital.
\end{abstract}

Palavras-chave: capital, violência simbólica, dominação, educação

\section{NEOLIBERAL IDEOLOGY AND EDUCATION: A EVEN CAN TO SOCIAL EMANCIPATION?}

\begin{abstract}
:
The violence in general is presented as a physical, resultant process of the use of the rude force. In the present article one searchs to argue as the movement of expansion of the capital, without breaching with the designated primate, the domination mechanisms had become maiss complex. Thus, one of the important components in the domination process economic politics and, contemporary, it is the exploration of the field of the symbolic manifestations as way to sediment on interests to the accumulation of the capital.
\end{abstract}

Words-key: capital, symbolic violence, domination, education

É fartamente conhecida a hipótese de Marx e Engels, em A Ideologia Alemãa, de que a classe que domina materialmente, também encontra necessidade de dominar ideologica e politicamente. Apresentada há mais de cento e cinqüenta anos, o século XX confirmou amplamente a referida hipótese uma vez que, na cotidianidade, se manifesta, senão com clareza, pelo menos com intensidade, a construção de mecanismos de dominação cuja finalidade é manipular, seduzir e integrar à ordem social.

Porém, a constatação empírica desse fato, de resto perceptível através do amplo debate hoje existente sobre a mídia e os meios de comunicação, não deve obscurecer que a dominação à qual se faz referência ocorre no interior da sociedade de classes. $O$ que significa reconhecer que atende a interesses específicos de legitimação da ordem instituída, ainda que os interesses, através dos quais se busca garantir a hegemonia de 
determinada classe, não sejam geralmente percebidos enquanto tais pela totalidade dos indivíduos de um determinado ordenamento social.

Com isso se está distante da pretensão de afirmar que os mecanismos de coerção direta tornaram-se desnecessários para a manutenção da dominação de classes no capitalismo avançado. O uso da força física, em geral manifesto através do uso de armas e tropas militares, entre outros meios, continua, no limite, essencial ao funcionamento da dominação de classes, sem, contudo, constituir-se em forma de ação exclusiva adotado por aquelas que, em determinado momento sócio-histórico, detém o controle privado das formas de dominação. Como observou a análise de Antonio Gramsci a respeito do capitalismo que se desenvolvia no século XX, operava-se cada vez mais, através da esfera do Estado, o binômio da coerção mais consentimento, como caminho para se obter a legitimação de determinado ordenamento social e a sua conseqüente aceitação. Mecanismo que pode ser detectado, por exemplo, no conjunto da charge que segue.

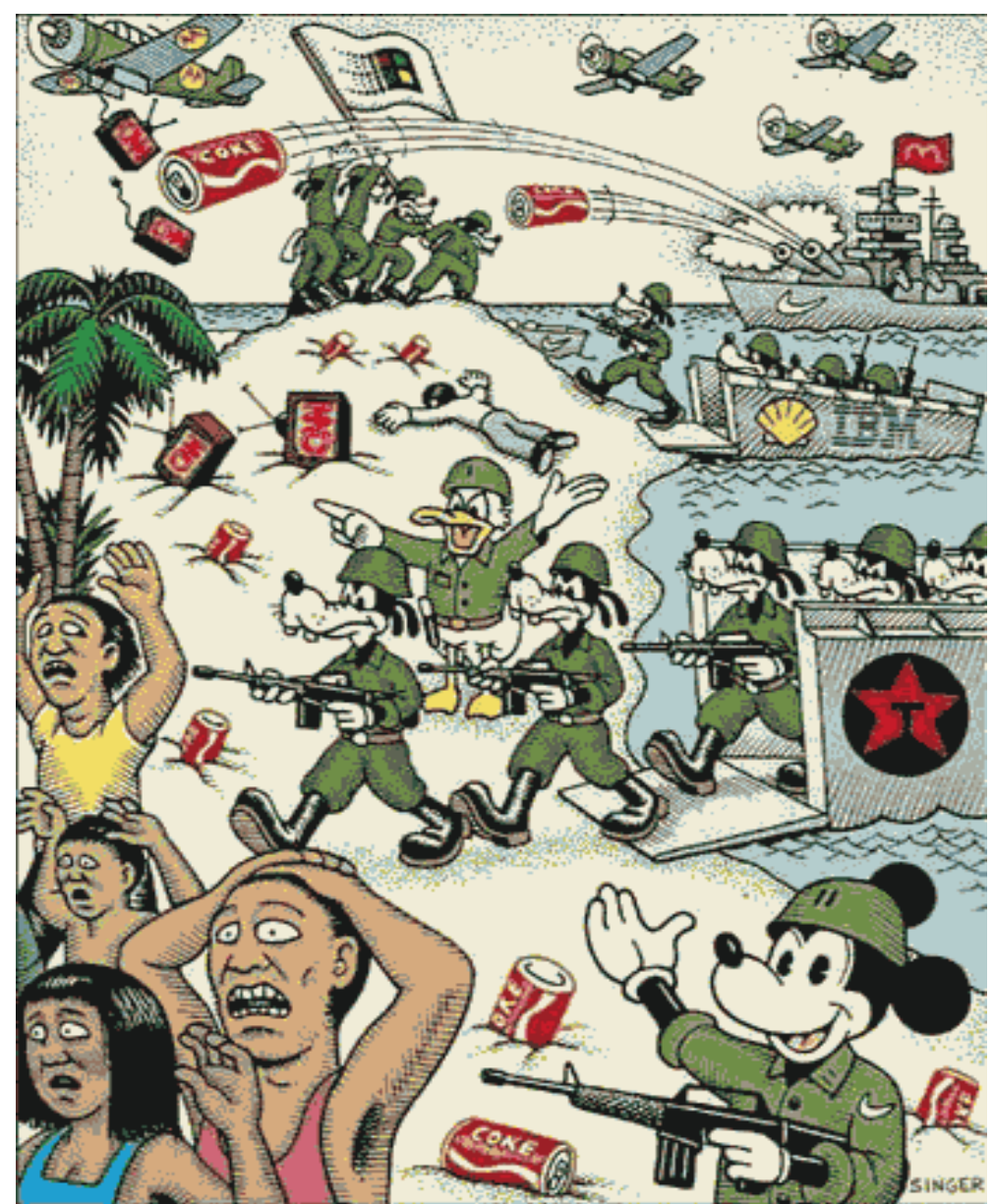

http://framos.wordpress.com/2008/03/06/reflexoes-imageticas-1/

A cena, na referida charge, é clássica: tropa de mariners norte-americanos desembarcando em alguma região periférica do globo, gerando morte para alguns, terror e rendição para outros. Mickey acena, como a dizer "olaaaaa....., chegamos para trazerlhes uma vida melhor", ainda que, ao fundo, o contradigam o general Patinhas e um exército representados pela legião de Patetas, ou seja, "os de baixo" executando cegamente as ordens daqueles que realmente realizam seus interesses com a invasão, isto é, o capital. Juntamente com a violência direta, aporta o mecanismo de 
manipulação, sedução e incorporação necessário ao processo de produção e reprodução do capital. Assim, na mesma charge, desembarcam junto com as tropas, comandadas pelo general Patinhas, o ideário da sociedade de consumo, confundido com o ideário da construção da liberdade. Outro não é o sentido do navio Mac Donalds, que parece sorrir quando se observa o par de canhões lançando refrigerantes em direção à praia e, um pouco mais abaixo, o símbolo da Nike, posicionado de modo estratégico, como se fossem lábios. Acrescente-se a presença da bandeira de paz da Microsoft; os barcos das grandes corporações, tais como Shell e Texaco, ligadas ao petróleo e IBM, do setor de informática, conduzindo as tropas; o estilo de vida da geração Coca Cola e, evidentemente, para garantir que tudo seja interiorizado na consciência coletiva, a necessidade de generalização de aparelhos de televisores com o emblemático logotipo da CNN.

Efetivamente, a dominação de classe, no período imperialista do capital, ganhou novas faces.Sem descartar o princípio da força, investe também, amplamente, nos mecanismos simbólicos, porém, igualmente concretos, para a construção da hegemonia dos novos dominantes. Efetivamente, opera no interior da construção dos mecanismos de dominação um processo mais sutil ao qual Pierre Bourdieu classifica como sendo de ordem simbólica ${ }^{\mathrm{i}}$.

Assim, a luta contra as formas de dominação reais estabelecidas no processo de hegemonia de uma determinada classe social e, no caso específico aqui referido, a que representa o capital é, igualmente, o embate pela destruição das violências simbólicas impostas aos que não detém os mecanismos de hegemonia social por aqueles que os monopolizam. Luta nem sempre travada, uma vez que, na base da violência simbólica, opera a ocultação das relações reais que os seres sociais estabelecem entre si, ao mesmo tempo em que, igualmente mistificada, se manifesta a materialidade dentro da qual tecem suas relações cotidianas. Processo cujo resultado acaba sendo o da aceitação das vontades impostas pelos interesses da classe dominante, assimilados, por aqueles que estão alijados deste mecanismo como sendo a realização, também, de seus interesses.

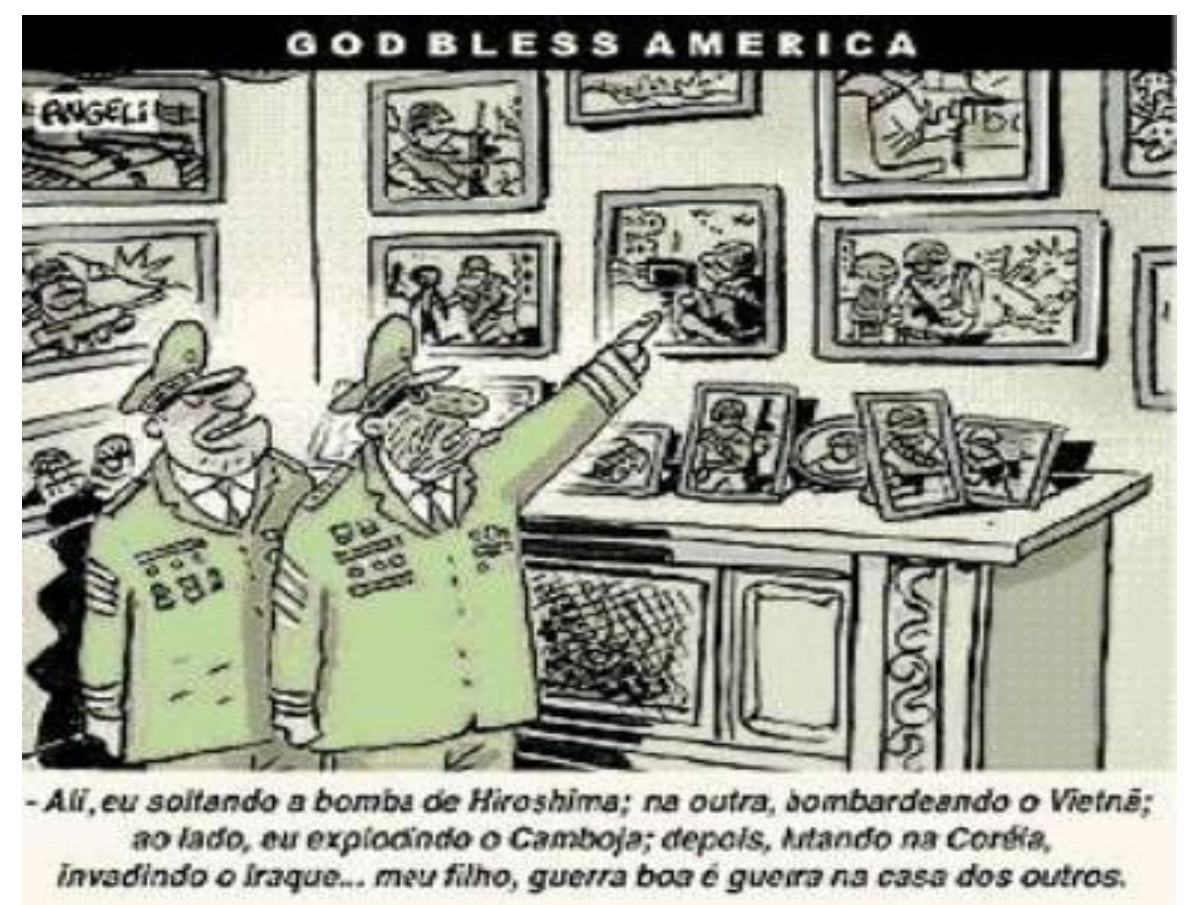

Revista HISTEDBR On-line, Campinas, n. Especial, p.26-38, mai.2009 - ISSN: 1676-2584 
http://www.opopssa.info/Imagens/ger_n8_ang.jpg

É diante dos efeitos provocados pelos mecanismos classificados como pertencendo à ordem simbólica, essenciais no processo de ocultação da realidade, que Bourdieu afirma:

[...] o conhecimento exerce, por si mesmo, um efeito - que me parece libertador -, todas as vezes em que os mecanismos de que ele estabelece as leis de funcionamento devem uma parte de sua eficácia ao desconhecimento, ou seja, todas as vezes em que ele toca nos fundamentos da violência simbólica. Essa forma particular de violência só pode de fato exercer-se sobre sujeitos de conhecimento, mas cujos atos de conhecimento, uma vez que são parciais $e$ mistificados, encerram o reconhecimento tácito da dominação implicada no desconhecimento dos fundamentos verdadeiros da dominação" $"$.

Os mecanismos de interiorização de ordem simbólica, os quais se corporificam naquilo que Bourdieu conceituou como habitus, ou seja, os mecanismos de disposição duráveis que permanecem mesmo após o desaparecimento do ato específico que os geraram, são incutidos por diversos meios. Porém, todos eles pressupõem um tipo de processo educativo, que pode ocorre de modo informal ou formal e, não raras vezes, articulado, cuja finalidade está direcionada a manter os mecanismos de controle por parte dos que, em determinado momento, impõem sua leitura de mundo ou, mais precisamente, seu arbitrário cultural. Usando abusivamente das reflexões bourdieusianas, que contemplam o espaço micro-sociológico, é possível afirmar que, hoje, mais do que o neoliberalismo, o capital constitui o núcleo do arbitrário dominante, expresso desde a mais de uma década na formulação do pensamento único, como se outro mundo não fosse possível. Cite-se, por exemplo, a título ilustrativo da força dos mecanismos de dominação simbólicas que, ressalte-se ainda uma vez, não estão dissociados das condições concretas nas quais são produzidas e reproduzidas as relações sociais, a charge que segue. Ela permite visualizar o quanto aqueles que se encontram na parte de baixo da pirâmide social, introjetam, na cotidianeidade, valores de bons costumes forjados fora de seu próprio universo de classe. 


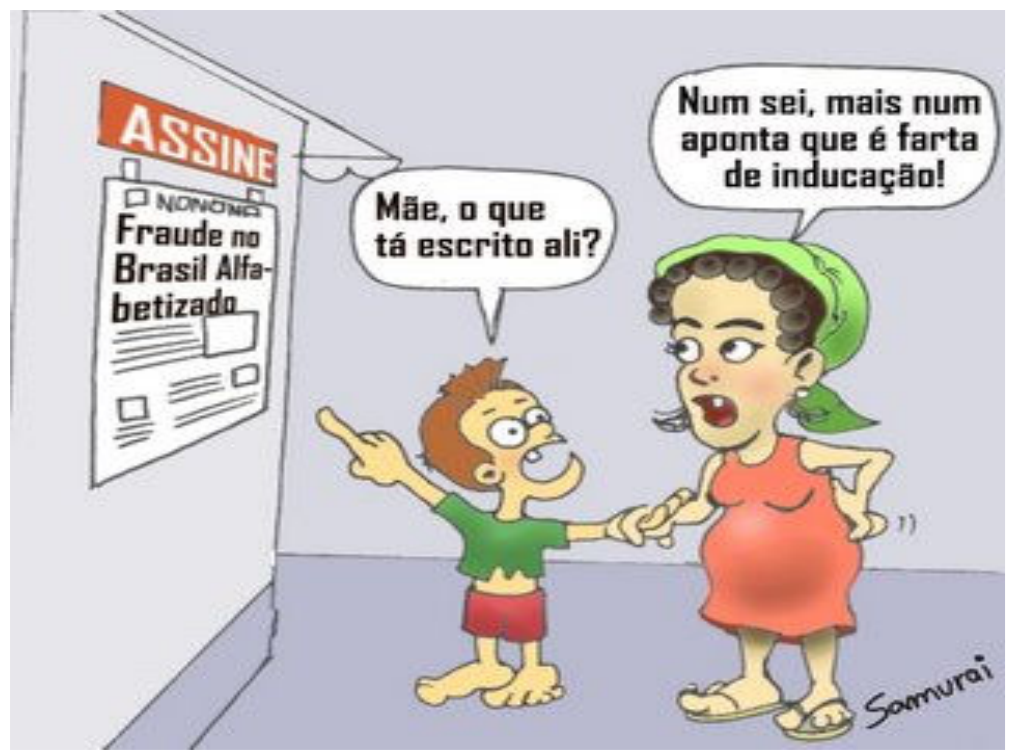

http://images.google.com.br/images?gbv=2\&hl=pt-BR\&q=chargista+samurai

O espaço social da educação formal, produzido pelo aparato escolar, e informal, do qual destaca-se a família e redes de relações de bairro, por exemplo (associações de bairro, comunidades eclesiais, entre outras instâncias) tem sido terreno fértil para a interiorização de um ethos, de modos de ver e de agir no mundo, que reforça os mecanismos de controle social e de manutenção da ordem (ainda que, em seu movimento contraditório, possam favorecer, também, o desenvolvimento de mecanismos efetivos de contestação desta mesma ordem), garantindo-se, assim, a perpetuação de certas relações sociais de dominação que, no caso concreto das sociedades contemporâneas, têm na acumulação de capital sua principal expressão. Mas, sua operacionalização só tem se tornado possível na medida em aqueles que se encontram alijados desses mesmos mecanismos os aceitam como legítimos e desejáveis. Exemplo de terreno fértil para que os mecanismos de dominação social se operacionalizem pode ser extraído do projeto de implantação do neoliberalismo.

Pode-se estabelecer uma série de julgamentos morais ao projeto neoliberal, desde aqueles que remetem ao desmantelamento progressivo de várias conquistas sociais até às formulações que potencializam a necessidade de acirrar a idéia de que o homem é o lobo do homem e que, portanto, cada um deve encontrar individualmente os seus caminhos. É possível, igualmente, acentuar, as conseqüências negativas desse projeto para a sociabilidade contemporânea e para os trabalhadores, em particular.

Entretanto, forçoso é reconhecer que esse projeto, para ser aceito, impõe a interiorização de sua "necessidade" nos múltiplos poros do espaço social e, não apenas, sobre o conjunto da classe trabalhadora. Afinal, é preciso que o próprio dominante se convença da legitimidade de sua dominação. Fato que pode ser observado quando se considera a vitória de Margareth Tatcher, na Inglaterra, no final dos anos 1970. Tatcher acentua, em suas memórias, que para obter a aprovação dos diversos setores sociais que compõem a sociedade inglesa à sua candidatura e proposta de governo, precisou mobilizar um conjunto de mecanismos de convencimento. Dentre estes mecanismos destacava-se aquele voltado a demonstrar, ainda que não fosse verdadeiro, que as greves naquele país eram excessivas e que acabavam sendo prejudiciais ao desenvolvimento da economia e à manutenção e ampliação dos empregos. Por caminhos socialmente 
perversos, efetivou-se "a aparência de unanimidade que constitui o essencial da força simbólica do discurso dominante",iii.

Certamente, para a operacionalização dos intentos perseguidos pela acumulação capitalista, nas práticas neoliberais, ainda que não permaneçam restritas a elas, o recurso à simplificação da realidade foi essencial no processo organizativo proposto. Era necessário atingir as massas de trabalhadores e aos demais estratos sociais e, nesse caso, não se tratava de desvendar os problemas econômicos e sociais na Inglaterra no final dos anos 1970 à luz do reconhecimento da crise do capitalismo aberta, fundamentalmente, no início da mesma década.

Usando de um traço básico da cotidianeidade, isto é, o terreno das alternativas e soluções pragmáticas, cujo resultado é, sobretudo e, em geral, o obscurecimento do caráter real das relações e das contradições sociais, Tatcher, em sua prática discursiva, logrou induzir à formatação de uma resistência coletiva, que estivesse presente em todos os segmentos de classe, ou que aparecesse enquanto tal, à série de greves que marcavam o território inglês nos anos 1970 e, com isso, abrir o caminho para conduzir o projeto neoliberal, dessa vez, enquanto poder de Estado. Afinal:

"É infinitamente mais fácil tomar posição a favor ou contra uma idéia, um valor, uma pessoa, uma instituição ou uma situação, do que analisar em que consistem na verdade, em toda a sua complexidade. [Entretanto, as] realidades históricas são sempre enigmáticas e, sob sua aparente evidência, difíceis de decifrar. [Portanto] a análise rigorosa das situações e das instituições é sem dúvida o melhor antídoto contra as visões parciais e contra todos os maniqueísmos muitas vezes associados às complacências farisaicas do pensamento 'comunitarista' -, que, através das representações que geram e das palavras em que se expressam, são freqüentemente carregados de conseqüências mortíferas" ${ }^{\text {,iv }}$.

O conhecimento da realidade jamais é imediato e, sim, mediato. Isso significa que a apreensão da vida social, em toda a sua complexidade, exige que se opere continuamente com o princípio da visão, momento empírico, fenomênico, aparente, e o princípio da divisão, resultando, da articulação de ambos, as possibilidades de apreensão de determinada realidade em sua manifestação concreta e que constitui o ponto de partida para outras sínteses, configurando a vida social como um "complexo de complexos", para utilizar aqui expressão forjada por Georg Lukács.

É caminhando para além do imediato, dentro do princípio da visão e da divisão, e da compreensão dos complexos, acompanhada do devido entendimento do fluxo contínuo de mecanismos mistificadores da realidade social, que se torna possível desvendar os impactos sociais de decisões desenvolvidas na esfera política para realizar interesses econômicos, "educativamente" mascarados, como sugere, por exemplo, a charge abaixo. 


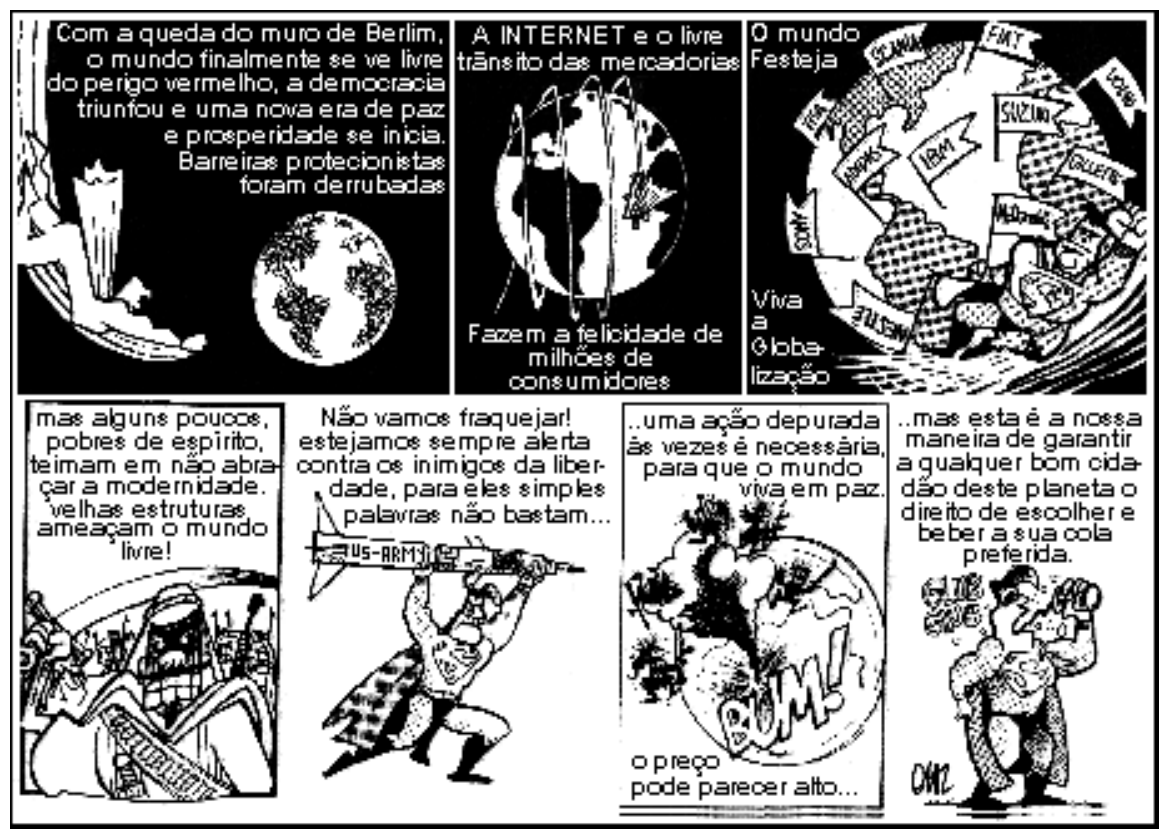

http://images.google.com.br/images?hl=pt-

$\mathrm{BR} \& \mathrm{q}=$ charge + sobre + globaliza $\% \mathrm{C} 3 \% \mathrm{~A} 7 \% \mathrm{C} 3 \% \mathrm{~A} 3 \mathrm{o} \& \mathrm{gbv}=2$

Assim, o processo educativo (seja ele formal ou informal), coloca, mais uma vez, novos desafios, caso adote a perspectiva de que "um outro mundo é possível", aliada ao reconhecimento de que uma outra educação (formal e informal), também é possível. Mais ainda, imprescindível, no sentido de resgatar o núcleo racional de análise da realidade social.

Trata-se, pois, de investir no sentido contrário ao da educação para a globalização,cujo horizonte está dado pela formatação de seres "empregáveis" ou que se transformam em "capital humano". São idéias-força que "educam", no sentido de transmitirem valores, princípios e, até mesmo, uma suposta nova ética social a ser incorporada no plano da sociabilidade mas que, na prática, encerram os indivíduos na redoma de vidro do "cada um por si", ou dos "competentes" e "incompetentes" para viverem no mundo contemporâneo.

Cite-se, por exemplo, que, no núcleo do pensamento neoliberal, concorrer por um emprego, contrapondo trabalhadores individuais a outros na mesma situação de desemprego ou disputa por um cargo mais elevado no interior de uma empresa, utilizando-se de todos os meios possíveis, deixa de ser uma dimensão perversa da sociabilidade contemporânea para erigir-se em princípio básico a ser seguido por todos aqueles que buscam demonstrar possuir a "capacidade de iniciativa" e de "empregabilidade".

$\mathrm{O}$ peso dessas idéias-força que alimentam a educação formal e informal dos indivíduos ou grupos de indivíduos no plano da vida cotidiana, adaptando-os para viver no mundo moderno, é destacado com justeza por Bourdieu, ao afirmar:

“'globalização':é um mito no sentido forte do termo, um discurso
poderoso, uma 'idéia-força', uma idéia que tem força social, que
realiza a crença. É a arma principal das lutas contra as conquistas do
welfare state: os trabalhadores europeus, dizem, devem rivalizar com
os trabalhadores menos favorecidos do resto do mundo. Para que isso 
aconteça, propõe-se como modelo, para os trabalhadores europeus, países em que o salário mínimo não existe, onde operários trabalham 12 horas por dia por um salário que varia entre 1/4 e 1/15 do salário europeu, onde não há sindicatos, onde as crianças são postas para trabalhar, etc. E é em nome desse modelo que se impõe a flexibilidade, outra palavra chave do liberalismo, isto é, o trabalho noturno, o trabalho nos fins de semana, as horas irregulares de trabalho, coisas inscritas desde toda a eternidade nos sonhos patronais. De modo geral, o neoliberalismo faz voltar, sob as aparências de uma mensagem muito chique e muito moderna, as idéias mais arcaicas do patronato mais arcaico. (Algumas revistas, nos Estados Unidos, estabelecem um quadro de honra desses patrões aguerridos, que são classificados, como o seu salário em dólares, de acordo com o número de pessoas que eles tiveram a coragem de demitir). É característico das revoluções conservadoras, a dos anos 30 na Alemanha, a de Tatcher, Reagan e outros, apresentar restaurações como revoluções. A revolução conservadora assume hoje uma forma inédita: não se trata, como em outros tempos, de invocar um passado idealizado, através da exaltação da terra e do sangue, temas arcaicos das velhas mitologias agrárias. Essa revolução conservadora de tipo novo tem como bandeira o progresso, a razão, a ciência (a economia, no caso), para justificar a restauração e tenta tachar de arcaísmo o pensamento e a ação progressistas. Ela constitui como normas de todas as práticas, logo como regras ideais, as regularidades reais do mundo econômico entregue à sua lógica, a alegada lei do mercado, isto é, a lei do mais forte. Ela ratifica e glorifica o reino daquilo que se chama mercados financeiros, isto é, a volta a uma espécie de capitalismo radical, cuja única lei é a do lucro máximo, capitalismo sem freio e sem disfarce, mas racionalizado, levado ao limite de sua eficiência econômica pela introdução de formas modernas de dominação, como a pesquisa de mercado, o marketing, a publicidade comercial. Se essa revolução conservadora pode enganar, é porque (...) ela se enfeita com todos os signos da modernidade (...) Foi armando-se da matemática (e do poder da mídia) que o neoliberalismo se tornou a forma suprema da sociodicéia conservadora que se anunciava, há 30 anos, sob o nome de 'fim das ideologias', ou, mais recentemente, de 'fim da história'”

A ilustrativa passagem de Bourdieu, que remete à formatação do que se convencionou chamar por "pensamento único" ou "Consenso de Washington", permite pensar o quanto o ideário neoliberal está nas antípodas dos referenciais que pensam a construção de seres sociais verdadeiramente críticos e educados (formal e informalmente) para refletir sobre a realidade que têm diante de si. Motivo pelo qual o terreno do neoliberalismo e da lógica do capital, em seu conjunto, não pode ser elencado como alternativa viável da perspectiva para o conjunto da humanidade. Efetivamente, homogenização das consciências e pensamento único estão distante de formar o par necessário para a discussão dos verdadeiros problemas sociais e humanos. 


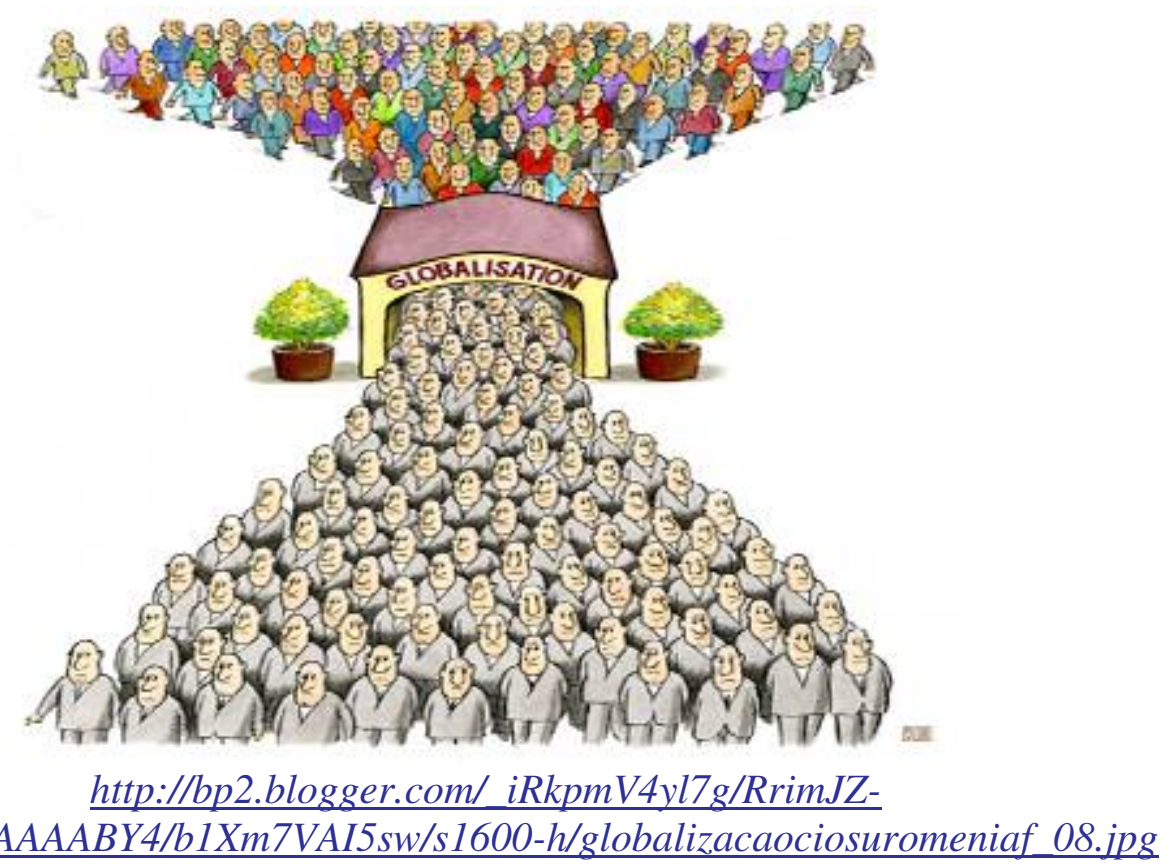

Ideário que busca, por todos os meios possíveis, eliminar os poros de contestação social, tornando-os, aparentemente, inexistentes, a fim de que possa ser veiculada a leitura de mundo necessária à continuidade das relações de dominação. Ironicamente, poder-se-ia dizer que esse ideário - o neoliberal e, mais genericamente, o do capital - aceita as divergentes posições que emanam dos poros da vida social desde que, é claro, elas não contradigam, em essência, o próprio pensamento único, ou seja, os esforços de transmissão de um determinado arbitrário cultural que os detentores da hegemonia buscam internalizar na totalidade da vida social, conforme ilustrado pela charge que segue.

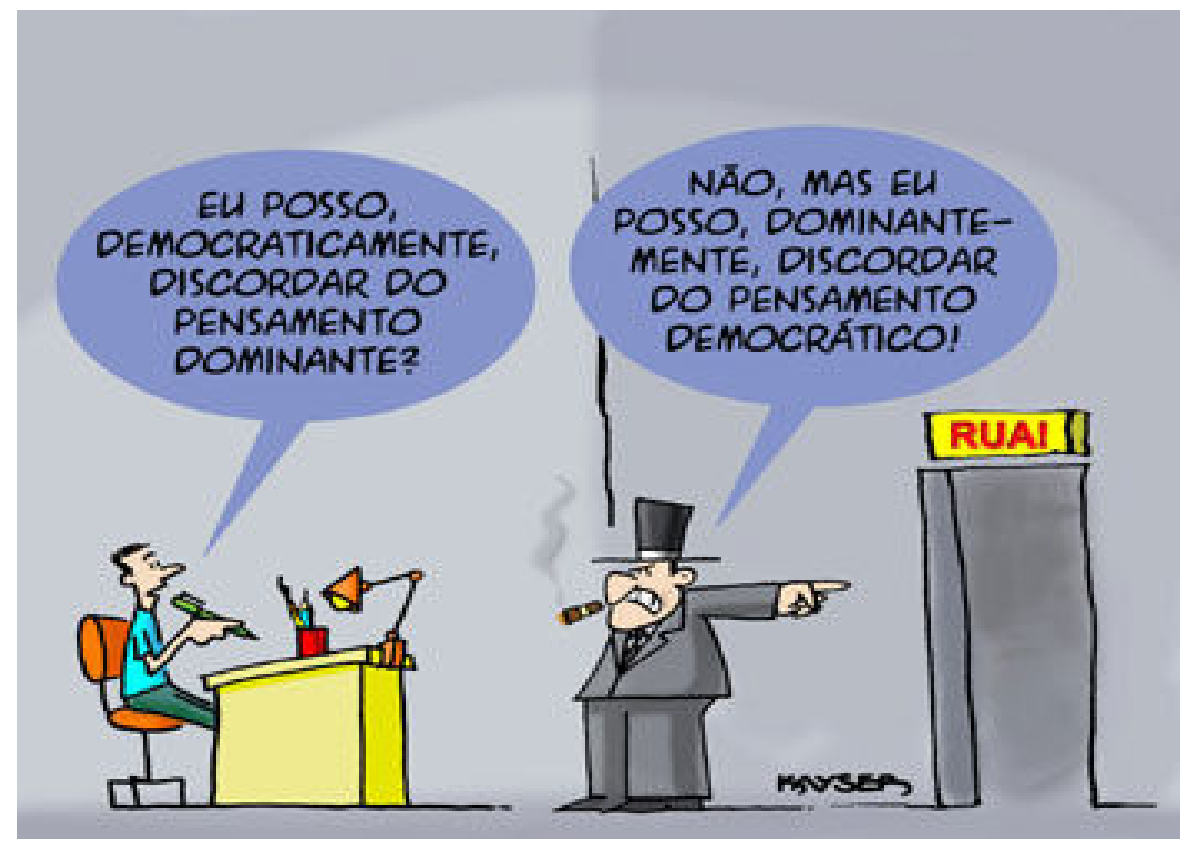

http://images.google.com.br/images?gbv=2\&ndsp=18\&hl=ptBR\&q $=$ charge + sobre + midia $\&$ start $=126 \& s a=N$ 
Sem desconsiderar que a base da vida social são as relações materiais de produção que nela se desenvolvem, há de se considerar, contudo, a importância que assume cada vez mais, no estágio tardio do capitalismo, a dimensão ideológica, entendida, aqui, no sentido lukacsiano e não enquanto falsa consciência. Como observa Lukács:

"[...] Gramsci tinha toda razão quando observava a esse respeito que nós,em geral, usamos a palavra ideologia em dois significados inteiramente diferentes. De um lado, trata-se do dado real (...) de que na sociedade cada homem existe numa determinada situação de classe à qual naturalmente pertence a inteira cultura de seu tempo; não pode assim haver nenhum conteúdo de consciência que não seja determinado pelo 'hic et nunc' da situação atual. Por outro lado, originam-se desta posição certas deformações, razão pela qual nos habituamos a entender a ideologia também como reação deformada em face da realidade. Creio que devemos manter separadas estas duas coisas quando usamos o termo ideologia" . [Assim, com] base nas coisas que conheço, posso exercer certa influência modificadora sobre a realidade externa, cujas leis agem independentemente de mim, de modo que, deste ponto de vista, enquanto produtor na economia, artista ou filósofo, encontro-me em oposição a uma realidade unitária, a qual, por sua vez, deve ser compreendida no sentido de uma identidade de identidade e não-identidade" ${ }^{\text {"vi }}$.

A vida cotidiana coloca os problemas ideológicos a serem respondidos pelos seres sociais em tempos determinados, dentro de situações determinadas. E, dentre as respostas, o campo da educação formal se revela essencial no que concerne à organização de uma nova cultura. Sobretudo quando considerado que as experiências burguesas neste terreno, para ficar-se restrito a elas, têm proliferado em ritmo intenso e avassalador, sem que seja produzida, em geral, a devida crítica quanto aos objetivos norteadores deste processo educativo, inclusive por nem sempre ser perceptível os caminhos pelos quais o capital educa e organiza sua leitura de mundo para o conjunto da humanidade. Assim, é freqüente, no processo educativo formal, mas também no informal, a defesa incondicional da cidadania, colocando-se o cidadão como o limite possível para a sociabilidade humana. Ressalte-se ainda o uso generalizado e não devidamente problematizado do conceito de "comunidade", esvaziado de seu sentido conceitual e forjador de uma pretensa sociedade de homens iguais, ainda que isolados em seus agrupamentos específicos: bairros, favelas, tribos, entre outros.

Neste sentido, diante dos mecanismos cada vez mais sutis de dominação social, encerrando os seres em formas de sociabilidade que os aprisiona em um mundo aparentemente sem saída e aos quais estariam condenados a viver indefinidamente, impõe-se, mais uma vez, a necessidade de se pensar, criticamente, o terreno da educação formal e informal e as possibilidades que elas apresentam de construir um outro mundo possível. Perspectiva que, com propriedade, faz-se presente em Mészáros, que a resgata, por sua vez, de José Martí, segundo a qual "as soluções não podem ser apenas formais. Precisam ser essenciais".

No campo da essencialidade impõe-se, por sua vez, o resgate das potencialidades contidas na "educação institucionalizada", a qual 
"serviu - no seu todo - ao propósito de não só fornecer os conhecimentos e o pessoal necessário à máquina produtiva em expansão do sistema do capital, como também gerar e transmitir um quadro de valores que legitima os interesses dominantes, como se não pudesse haver nenhuma alternativa à gestão da sociedade, seja na forma 'internalizada' (isto é, pelos indivíduos devidamente 'educados' e aceitos) ou através de uma dominação estrutural e uma subordinação hierárquica e implacavelmente imposta. ${ }^{\text {vii }}$

"As determinações gerais do capital afetam profundamente cada âmbito particular com alguma influência na educação, e de forma nenhuma apenas as instituições educacionais formais. Estas estão estritamente integradas na totalidade dos processos sociais. Não podem funcionar adequadamente exceto se estiverem em sintonia com as determinações educacionais gerais da sociedade como um todo. Aqui a questão crucial, sob o domínio do capital, é assegurar que cada indivíduo adote como suas próprias as metas de reprodução objetivamente possíveis do sistema. Em outras palavras, no sentido verdadeiramente amplo do termo educação, trata-se de uma questão de 'internalização' pelos indivíduos (...) da legitimidade da posição que lhes foi atribuída na hierarquia social, juntamente com suas expectativas 'adequadas' e as formas de conduta 'certas', mais ou menos explicitamente estipuladas nesse terreno. Enquanto a internalização conseguir fazer o seu bom trabalho, assegurando os parâmetros reprodutivos gerais do sistema do capital, a brutalidade e a violência podem ser relegadas a um segundo plano (embora de modo nenhum sejam permanentemente abandonadas) posto que são modalidades dispendiosas de imposição de valores (...) Apenas em períodos de crise aguda volta a prevalecer o arsenal da brutalidade e violência, com o objetivo de impor valores" "viii.

Diante do exposto, portanto,
"desde o início o papel da educação é de importância vital para romper com a internalização predominante nas escolhas políticas circunscritas à 'legitimação constitucional democrática' do Estado capitalista que defende seus próprios interesses. Pois também essa 'contra-internalização' (ou contraconsciência) exige a ordem existente" ${ }^{\text {"x }}$.

Seguramente, a tarefa a ser realizada encontra-se entre as mais complexas, da perspectiva de construção da humanidade verdadeiramente humana. Afinal, como observam McLaren e Farahmandpur,

"O capitalismo tornou-se tão intenso que ele reprime nossa habilidade de conhecer o processo de repressão em si. Ele naturaliza a repressão tão completamente, que o horror econômico é visto como parte da perversão e da distorção diárias das coisas (...) e, conseqüentemente, falhamos em tratar as implicações predeterminadas das capacidades destruidoras do capitalismo. Além disso, o capital é mais do que violência sublimada afunilada em parques temáticos de fantasias e da segurança de paradis artificiels

Revista HISTEDBR On-line, Campinas, n. Especial, p.26-38, mai.2009 - ISSN: 1676-2584 
suburbanos, é o horror vivo daqueles/daquelas que devem suportar a força bruta da opressão"x.

Entretanto, por mais totalizantes que pretendam ser estes processos, ainda é característico do humano a capacidade de oferecer respostas que nos distanciem da barbárie cotidiana e de sua banalização e incompreensão.

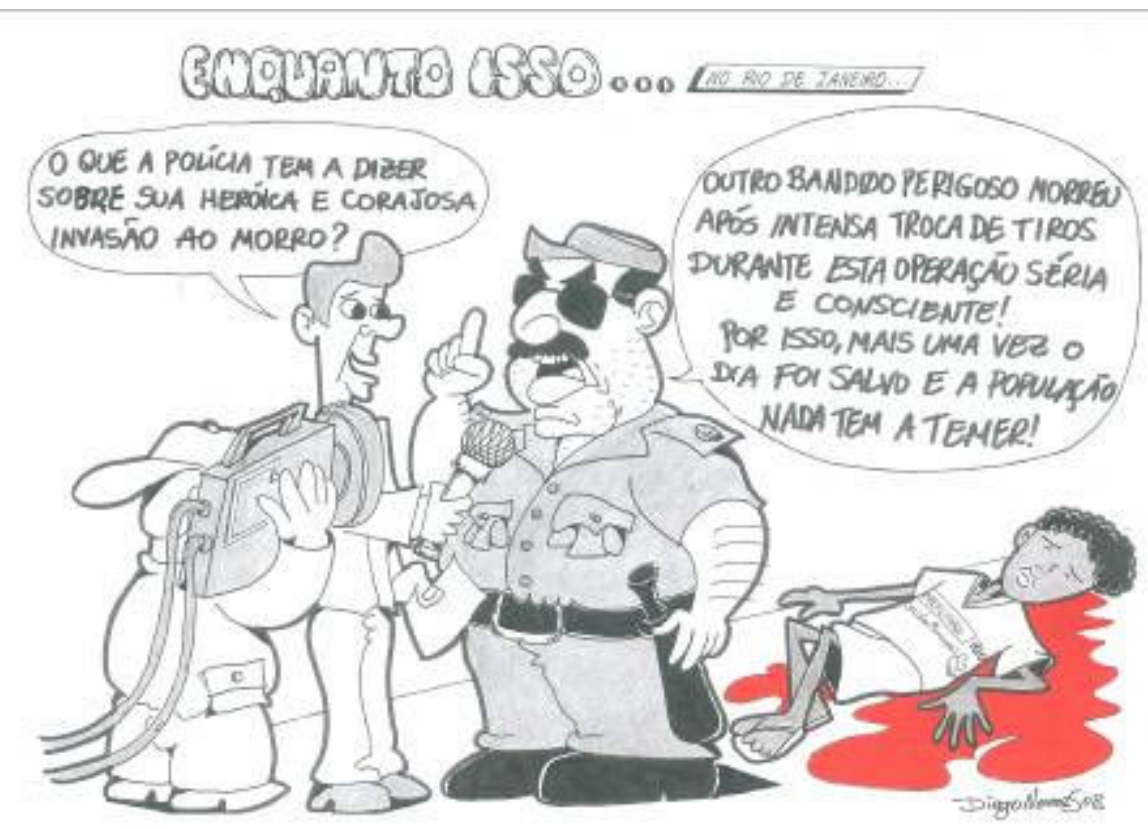




\section{BIBLIOGRAFIA}

BOURDIEU, Pierre (1994), Lições da Aula, R. J., Vozes, p. 19-20

BOURDIEU, Pierre (1998), Ao leitor, in Contrafogos, R. J., Jorge Zahar Editor. (1998), Com a palavra, o ferroviário, in Contrafogos, R. J., Jorge Zahar

\section{Editor.}

BOURDIEU, Pierre, L'État e la concentration Du capital symbolique. In THERET, Bruno (org.) (1995), L'État, la finance ET Le social, Paris, Éditions La Découverte.

LUKÁCS, Georg (1969), Ser e Consciência, in ABENDROTH, Wolfgang (org.), Conversando com Lukács, R.J., Paz e Terra.

MÉSZÁROS, István (2005), A Educação Para Além do Capital, S.P., Boitempo Editorial.

MACLAREN, Peter e FARAHMANDPUR, Farah (2001), Pedagogia Revoluconária na Globalização, R. J., DP\&A Editora.

\footnotetext{
i - «A ordem simbólica repousa sobre a imposição ao conjunto dos agentes de estruturas estruturantes que devem uma parte de sua consistência e de sua resistência ao fato que elas são, ao menos em aparência, coerentes e sistemáticas e que elas são objetivamente em consonância com as estruturas objetivas do mundo social. É este acordo imediato e tácito ( em tudo oposto a um contrato explícito) que funda a relação de submissão doxica que nos liga, por todos os ligamentos do inconsciente, à ordem estabelecida. O reconhecimento da legitimidade não é, como acredita Max Weber, um ato livre da consciência clara. Ele se enraiza no acordo imediato entre as estruturas incorporadas, tornadas inconscientes, como aquelas que organizam os rítmos temporais (por exemplo, a divisão em horas, totalmente arbitrária, do emprego do tempo escolar) e as estruturas objetivas ». BOURDIEU, Pierre, L'État e la concentration Du capital symbolique. In THERET, Bruno (org.), L'État, la finance ET Le social, Paris, Éditions La Découverte, 1995, p. 92.

ii - BOURDIEU, Pierre, Lições da Aula, R. J., Vozes, 1994, p. 19-20)

iii - BOURDIEU, Pierre, Ao leitor, in Contrafogos, R. J., Jorge Zahar Editor, 1998, p. 8.

iv - BOURDIEU, Pierre, Com a palavra, o ferroviário, in Contrafogos, R. J., Jorge Zahar Editor, 1998, p. 35-36.

` - LUKÁCS, Georg, Ser e Consciência, in ABENDROTH, Wolfgang (org.), Conversando com Lukács, R.J., Paz e Terra, 1969, p. 41.

vi - Id. Ibidem, p. 72. ${ }^{\mathrm{vi}}$ - LUKÁCS, Georg, Ser e Consciência, in ABENDROTH, Wolfgang (org.),

Conversando com Lukács, R.J., Paz e Terra, 1969, p. 41.

vi - Id. Ibidem, p. 72.

vii - Mészáros, István, A Educação Para Além do Capital, S.P., Boitempo Editorial, 2005, p. 35.

viii - MÉSZÁROS, ISTVÁN, A Educação Para Além do Capital, S. P., Boitempo Editorial, 2005, p. 43 44.

ix - MÉSZÁROS, ISTVÁN, A Educação Para Além do Capital, S. P., Boitempo Editorial, 2005, p. 61.

x - MACLAREN, Peter e FARAHMANDPUR, Farah, Pedagogia Revoluconária na Globalização, R. J., DP\&A Editora, 2002, p. 23.
}

Artigo recebido em: 10/12/2008

Aprovado para publicação em: 15/01/2009

Revista HISTEDBR On-line, Campinas, n. Especial, p.26-38, mai.2009 - ISSN: 1676-2584 